\title{
The "Flexible" Demand in Interior Design
}

\author{
Jing Zeng, Jingyi Chen \\ College of Forestry, Sichuan Agricultural University, Wenjiang 611130, China
}

Keywords: environment; modern interior design; decoration project

\begin{abstract}
Nowadays with the modern pace of life gets faster and faster, people's demand towards the superior living environment turns to be higher and higher, and the modern interior design needs to make further progress. On one hand, it always takes several months to finish a set of interior design, ranging from the construction work to putting into use, and meanwhile due to the waste gas (such as methanol), waste materials and so on left from decoration project would have an effect on people's health, the environment protection and energy saving are increasingly becoming the emphasis concerned by people. On the other hand, with the acceleration of the variation of fashion trend in the market, people may be fond of various kinds of things, resulting in the greater demand towards the flexibility of interior space. In addition, it will consume plenty of manpower, material resources and time in traditional decoration project, i.e. treating walls and ground, installing pipelines and ceilings, flooring and such, making resource waste and environmental pollution unavoidable. More flexible and versatile "flexible" factors in interior design are more and more demanding by people.
\end{abstract}

\section{Demand in modern interior design}

\subsection{Flexible demand in interior design of public space}

\subsubsection{Demand of variable design in interior space of public buildings}

The interior space design in public buildings is mainly specific to the concept of space. Designers need to design the space in public buildings, and such space refers to the area where people get involved in activities. This space is common to people, that is to say, this space is for public use for everyone.

In the modern sense, public buildings mainly include shopping mall, gymnasium, natatorium, library, airport, passenger station and so on. Generally human factors are required to consider during the process of designing interior space for these public buildings. In view of the major function for these public buildings is to serve and satisfy people, the set space could be hallway, rest area, auditorium, etc, so that in this way, people's rest and activity demands could be met. The interior space in public buildings is the main place for people to carry out behavioral activities at all events, all types of approaches and means shall be adopted in terms of the design for the sake of satisfying all groups of people and allowing them to carry out activities to the greatest extent, and thus the usage rate could be promoted.

The public space needs to accommodate a mass of human traffic and contain different functional demands, and meanwhile, it will be difficult to reconstruct the interior space. There are three reasons for the difficulty of reconstruction: first of all, because of the large work amount and fairly long time-consuming, people's activities would be influenced; secondly, there will be relatively large quantity of pollutants, loud noise and plenty of air pollution, and it will be difficult to cut off these stuff; thirdly, every day the flooded stream of people will be a giant test to the durability of indoor material, so that the solid foundation must be constructed for public space. The excellent space design is just like a small but steady stream, waiting people to taste slowly and carefully. ${ }^{[1]}$ However, as the time goes by, the masses may change their preference, under the circumstance of ensuring normal usage, the public space also needs to maintain certain freshness, which involves with variable design to small part. 


\subsubsection{Demand of flexible design in exhibition space}

The design in exhibition space is featured by powerful liquidity and this characteristic could be the maximal one, as a result, the fundamental principle is to adopt the dynamic, serialized and rhythmical exhibition form in the first place, which is determined by the nature of exhibition space and human factors. The exhibition space must arrange audience's visiting flow in the most reasonable approach, allowing audience to get involved in exhibition activities comprehensively and economically, it shall try to avoid or walk few repeated routes, and particularly to avoid repeated routes in the exhibited key areas. Designers shall live up to make the spatial processing like a smooth, cadenced, clear and organized melody, in this way the entire design could be logical and well-reasoned. By the time of meeting the functions, the charm of space variation and infinite interest of the design shall be experienced. Furthermore, the exhibition space needs to attract crowd's attention more and leave audience profound impression.

Various types of exhibits require varied exhibition space designs to serve as a foil and show up, but it will be difficult to use the planning layout of the same kind to satisfy the demands of different exhibits within the same space. In the meantime, a good deal of material waste will be generated from repeated decoration and dismounting work. Hence, the layout in exhibition space ought to be more flexible.

\subsubsection{Demand of convenient design in the space with business nature}

For the business space, such as the clothing shop, restaurants, shops and so on, a certain sum of business loss will be produced if the decoration period is too long.

Nowadays, there are many old restaurants which have been operated for more than ten years, most of these restaurants are fully old-fashioned in interior decoration, a lot of damages could be seen on the painted walls and wooden ground, and the problems such as falling ceilings, plenty of dust in smoke exhaust and exhaust outlet, dim light and so on are obvious, the tables, chairs, attic, stairs and even the cooking bench in the kitchen are not well protected. ${ }^{[2]}$

The nice catering space enables consumers to build up appetite and to keep joy while dining, and the cozy catering environment could attract consumers' attention. However, the interior decoration in these old stores is unable to satisfy the current usage demand any longer, it is not clean, tidy and beautiful enough, the smoke, light and other problems take full effect on the dining atmosphere. The modern and new consumers could not be attracted by the outmoded design. In addition, as the furniture, tableware, kitchen ware and such are almost reaching to the limit usage of age, they ought to be changed for new. However, for these catering spaces with relatively booming business, the giant loss is bound to be caused from closing shops for dozens of days and doing interior decoration work.

In recent years, some of the public space designs have noticed these problems, therefore, a new kind of decoration style---industrial style has gained favor. A wide variety of clothing shops, cafes, restaurants and others have selected this style. Seeing from the construction materials, most of the walls with industrial style have retained partial appearance in original building, for instance, the wall bricks are exposed without any decoration, or the brick design or paint decoration is adopted, or else the concrete walls are used as substitute; the indoor windows or beams are made into mottled rust shape, which seems very shabby; the design of ceiling material is hardly seen, and generally the exposed metal pipelines or sewer could be seen, the water pipes, electric wires and pipelines are arranged reasonably according to the color and location, all of these stuffs have constituted one of the visual elements in the home decoration with industrial style. The metallic framework, lamps and lanterns with double joints, as well as the bulbs with versatile types and electric wires knitted with cloth are the all-important elements in the decoration with industrial style. The concise and rough industrial style could be built; without the ceilings and sundry decoration, the cost could be saved and the host's character could be manifested; and also the decoration period could be saved by a large margin, in this way the space could be put into use rapidly. However, its boundedness lies in that it is unable to satisfy the demands with more design styles, and thus may resulting in the singleness in design style. The business space still requires convenient and versatile 
design methods.

\subsection{Interior design demand in the residence}

\subsubsection{Health demand in the residential space}

The residential space has offered body protection for human, and it not only prevents people from being hurt, but also contributes to the growth and health of body and mind, and perfect personal image. The residential space could free people from the pressure of fierce survival competition exteriorly, so that people could give play to their potentials in the comfortable space where belongs to oneself, and thus an approach could be provided for giving play to individual creativity. The residential space is considered to be the core zone where people's all levels of demands are met. Along with the improvement of people's living standard and the enhancement of environmental-protection consciousness, not only the beautiful and durable materials are required in the decoration project, also whether the materials are hazardous or not, the effect to human health and environment shall be concerned. ${ }^{[3]}$ However, in real life the pollution problem in home decoration has already become the "invisible killer" that endangers human health and safety severely, and it has turned into the third major air pollution issue in the world following "coal smoke pollution" and "photochemical pollution”. Hence, the paint with low methanal, quartz wall cloth, floor with lock catch and other green building materials are turning up constantly, and meanwhile suggestion of moving in after dozens of days is offered, so as to try to reduce the harm to human body from decoration pollution.

However, the interior decoration project could spend excessively long time, and to a certain extent, it will impact consumers to use. A majority of residences locate in apartment-type subdistricts, and the surrounding residents may re-decorate residences out of their needs of perfecting living condition and attempting new style, under such circumstance, the loud noise, enormous dust and so forth would have a strong impact on the living environment for these people.

\subsubsection{Hardbound residence is in vogue}

With the acceleration of people's pace of life, the hardbound residence has become a kind of trend gradually, it expands nationwide from the first-tier city rapidly, and its project proportion has been promoted by a large margin. Due to home buyers could move in just after buying furniture, the time that needs to be spent originally has been saved, and meanwhile there will be no need for these buyers to worry about the burdensome problems such as decoration style. More and more home buyers focus their sights on "hardbound house". It is reported that a majority of real estate will deliver the house in the form of "hardbound house" in the next few years.

It will be hard for the interior design of assembly-line type to satisfy the demands from all walks of consumers, many consumers who would like to pursue personality still need decoration or modification through traditional flow of interior design.

\subsubsection{Demands from users in the residential space}

The residential space in the city is restricted by economy, society, culture and environment, and it is also impacted by people's dwelling demands. However, because people's dwelling demands are always versatile and changing constantly, the architecture designers are required to create various kinds of residential space where people's versatile and variable demands could be met. The traditional residential space in China possesses relatively strong functional adaptation. Taking the quadrangle courtyard as the basic mode, the purpose to construct such space is to satisfy the living demands for the big family and its generation multiplying. In the beginning of the $21^{\text {st }}$ century, the factory owners built dormitory-type residential buildings for a large number of labors who came from rural areas, and such buildings become the rudiment in the residential space of modern city. In Shanghai, the most developed industrial city in China in the early times, developers built lane housing for middle class, and such housing belongs to the earliest residential space in the modern urban environment. The flexibility and adaptation in traditional residential space of China has already been lost. 
Sham Shui Po of HongKong is the place where many people are embraced together while coming to struggle for life. They live in the small houses less than 10 square meters and these small houses are called "coffin house, room in room, cage house". The so-called room in room refers to the owner or the middleman landlord divides a residential unit into relatively small independent units with the number of no less than two for selling or renting. Each small house covers about 10 square meters, the monthly rent is several thousand Yuan and the generally the tenants are grass-roots. Usually these people could not afford the expensive rent, or they are disqualified for getting public-operated houses. In general, these rooms in rooms are not according with fire-fighting articles, and meanwhile the environment is bad, many deadly fire disasters happened. A room in room holds a family of four, and the daily life, diet, children's homework and life of the whole family are carried out in such small space. The so-called coffin house refers to the space with coffin size just as its name implies, one even needs to curl up his feet while sleeping. It is very inconvenient to live in coffin house and people are easy to get strain on their muscles and bones. To live in cage house refers to live in cage for real. These residents could only use the toilet in common. These houses are very narrow, people even could not stand, and only the most basic demands such as sleep, washing, excretion and other demands could be met. People's increasing living demands could not be met, and people's safety and health demands in life could not be met, either. Furthermore, the activity space will be squeezed by gradual increase of articles for daily life. ${ }^{[4]}$ Most importantly, this kind of residences could not satisfy people's psychological demands, only the bright, comfortable residential environment could delight body and mind, and offer people the cozy atmosphere just like home.

The designers shall not only consider the growth of people's residential demands, they also need to consider the rise of people's spiritual demands. Meanwhile, how to apply the flexibility and adaptability featured by China's traditional residential space into modern design also needs to be taken into account.

\section{Design of flexible space}

For the sake of meeting the changes of people's demands, the design of flexible space has become a key design concept. The flexible space variation is able to meet more use demands, cope with more temporary changes in demands, and also promote the use ratio for the space.

\subsection{Flexible office space}

The design concept of "Flexible Office Space" has provided a new development thought for interior design.

Appeared in 2004, the "Flexible Office Space" originated from a kind of new office mode prevailed in Europe and America currently. As the office is the operation place and also one of the highest costs for the enterprise, the contradiction surrounded the use cost and function has always been perplexing many large and small-size enterprises in Europe and America over the years. The enterprises need to input relatively high cost and large one-off investment if they want to rent and decorate the offices so as to reach up to satisfied functions. It will be hard to use the offices with old decoration immediately due to the differences in function, style, layout and matching. These enterprises are forced to re-decorate, purchase and maintain equipment. Some enterprises would share the areas with relatively low usage rate such as meeting room, reception center, tea room and so forth, but although the operation, decoration and equipment input costs could be saved partially, many problems would turn up under the circumstance of coordinating and managing different demands. To be specific, the indoor decoration products will be fabricated in the factory in advance according to the actual metrical standard, people just need to assemble these finished modules just like building blocks after moving the products into offices, and dismounting, combining or changing the layout randomly could be done in accordance with the practical situation. The recycle and convenient adjustment of the modules could reduce decorate wastes greatly, save cost and more conform to the green concept of sustainable development. 


\subsection{Concealed space}

In order to increase the utilization rate of space in small apartment, designers compress, fold the functions such as sleep, dining, storing and others that are not frequently used, they even conceal these functions. In this way, the public space that carried with most activities in family will be enlarged and opened up.

For example, the Hutong room with kites transformed from $31 \mathrm{~m}^{2}$ to $155 \mathrm{~m}^{2}$ by designer $\mathrm{Li}$ Wanli has utilized the space to a large extent. In order to arrange the living and exhibiting space in the room reasonably, the areas of kitchen and toilet have been increased, the respective private space for a family of four with three generations has been ensured. By adopting the time dimension, space dimension, logic dimension and other multiple concepts, the designer divided different zones through moving and changing the partition plates, and set the change of five modes so as to adapt the using requirements towards different scenes. The new home after transformation has been changed into the one with five rooms, four halls, one kitchen and one toilet, and meanwhile a comfortable and independent space could be created for each family member, plus the transformed and multi-functional dining-table, custom-made working table made by kite, concealed dresser, classroom that could accommodate 40 persons to attend class at the same time, all of which have accumulated the designer's elaboration and ingenuity.

Let's take another example, the $60 \mathrm{~m}^{2}$ dwelling for six persons transformed by designer Liu Jinrui, the space occupation of parents' bed in daytime has been liberated by utilizing the mobile clothes closet and folding bed, and the PVC curtain has ensured the privacy for parents' and children's bedrooms in a nice way. Through calculating the dimensions of the kitchen and toilet accurately, the space for two-row manipulating platform and two toilets have been given, enabling the efficiency to be promoted threefold. The vertical space in original two bedrooms have been utilized to the maximum, and the independent rooms for boy, girl and parents have been arranged skillfully.

These cases possess two obvious characteristics, namely many members in the family and small indoor area. For the small apartment, it appears to be particularly important on how to promote the space flexibility. The design also starts from this point, seeks the concealed space to the utmost extent, completes the perfect fusion between active region and rest area and satisfies the change of people's demands in the room.

\section{3. "Flexible" development trend in interior design}

The "flexible" design refers to the one with more flexible, convenient space and decoration. Along with the technological progress and promotion of production level in industry, the sustainable development and green design concept are certain to become the emphasis for interior design. The flexible design will be associated with green design naturally.

Rather than refer to a complete set of design, the modular design refers to partial and fundamental decoration design. In a certain period, problems like long time-consuming and high material-consuming in traditional decoration project still exist in infrastructure such as wall, floor, ceiling, suspended ceiling and so forth. In order to stick to the concept of sustainable development, the contemporary designers ought to consider how to "subtract" in interior design thoroughly.

The wooden floor with lock catch is just a kind of "building-block type" design appeared in recent years. Its emergence enables interior design thought to move towards the development direction of convenience and environmental-protection. The common wooden floors with flat lock need to be connected with tackiness agent, which contains methanal and other chemical components. ${ }^{[5]}$ Indoor pollution would be caused in case of using too many such floors, and people may also worry about the insecure connection in case of using less tackiness agent. However, the wooden floor with lock catch could be paved without glue due to its locking function, and meanwhile the joint between floors is also very tight, problems such as crack, swelling out of the change of temperatures in four seasons will not be met. It is featured by fastness, stability and durability. In addition, it could be reused due to it could be paved without glue. The convenient and 
safe wooden floor fully accords with green design concept and has gained favor in market.

In most catering space, the interior decoration has adopted hanging and placing ways to decorate walls, roofs and space more, things are placed like building blocks, rather than traditional nailing and embedding way, so that by the time of protecting wall, the completeness of the material or decoration has been protected. It indicates that in case the host would like to change style, he just needs to buy and sell second-hand, in this way the utilization rate of the material has been increased greatly, the waste has been reduced and the flexibility in interior decoration has been promoted.

In order to adapt different space demands from users in different periods, the mobile plates and combined plates are utilized flexibly in interior design to divide space. Owing to the flexibility in "building-block type" design, there is no doubt that the modular design will contain more environmental-protection factors, reduce wastes and relieve economic burden.

\section{Acknowledgements}

Punds project: Key Laboratory of Wood Industry and Furniture Engineering of Sichuan Provincial Colleges and Universities

\section{References}

[1] Donald Arthur Norman.Emotional Design [M]2005.

[2] Kenya Hara. Designing Design [M]. Lars Mullre Publishers,2015.

[3] Zhao Ying. The Importance of Emotion in Interior Design [D] Inner Mongolia: Inner Mongolia Normal University,2009.

[4] James E. Gilliam and David Unruh. The Effects of Baker-Miller Pink on Biological, Physical and Cognitive Behaviour[J]. Journal of Orthomolecular Medicine Vol. 3. No. 4, 1988.

[5] Yuxiaoming. The application of ornamental plants in interior design [J]. Modern gardening, 2016, (9): 145-146. 